\title{
Do Not Resuscitate: An Argumentative Essay
}

\author{
Audai Nader Sa'id ${ }^{1 *}$ and Majd Mrayyan ${ }^{2}$ \\ ${ }^{1}$ King Hussein Cancer Center, Leukemia Unit, Senior Charge Nurse, Amman, Jordan \\ ${ }^{2}$ Professor and Consultant in Nursing Leadership and Hospitals Management, The Hashemite University/ Faculty of Nursing, Zarqa, Jordan
}

Received: September 23, 2015; Accepted: December 05, 2015; Published: December 20, 2015

*Corresponding author: Audai Nader Sa'id1, King Hussein Cancer Center/Leukemia Unit/ Senior Charge Nurse, Amman, Jordan; Email: Audai_saeed1@yahoomail.com

\begin{abstract}
The aim of this study to discuss the do not resuscitate order focusing on controversial opinions and to summarize the opponents and proponents opinions from the legal and ethical perspective.

There is a different opinion regarding to do not resuscitation. Nursing play an essential role in the discussion of do not resuscitation, and that does not mean patients will die alone and uncared, it means that the patient will be placed under hospice care when the end is near. Do not resuscitation is the way in which patient and family could reduce the long and painful time before he/she dies.
\end{abstract}

Keywords: Do not resuscitate ethical; Legal

\section{Introduction}

The primary health care provider goal is to restore patients' health as possible by maximizing benefits and minimizing harm [1]. Accordingly if treatment failed, the harm or burden will be more than benefits. On the other hand, if the competent patient refused treatment; that treatment is no longer justified [2]. Unfortunately, many physicians do not know their patients' preferences for resuscitation, and many patients have a poor understanding of their own resuscitation order [3].

Nurses as an essential part of the health care provider have always been beside of dying patients, their roles in providing the maximum quality of care and support for the remaining lifetime for both patients and their loved ones is traditional and expected [4]. The nurse's loyalty to the patient requires an expertise in the relief of physical, emotional, or spiritual suffering, which means the nurse's roles in discussions end of life choices with patients is imminent [5].

Death is defined in Black's Law Dictionary as an irreversible cessation of the vital functions, signs, circulation, and pulsation [6]. For that if your patient stops breathing or their heart stops beating in the hospital, it is generally felt that the morally best approach is to perform Cardiopulmonary Resuscitation (CPR). However, success is not always possible, and not uncommon, this procedure is associated with a high level of morbidity but it's must be ethically justified [7].

The CPR is an emergency procedure which is performed on patients with cardiac arrest in efforts to maintain life, rebuild health, and prevent disability [8]. While the DNR is a procedural term long used by doctors to refer CPR is not to be used as an intervention that has been described as a process to limit aggressive interventions that aim to save lives [9].

It is reasonable to tell hospitalized patients that if they undergo attempted CPR for cardiac arrest, the chance that they will leave the hospital alive is about $20 \%$, if the patients have chronic disease this percent decrease to $5-10 \%$ with a significant percentage of severe neurological deficits requiring chronic nursing home care [10].

The argumentative essay it's the process of using legal and ethical evidences attempting to persuade others, expressing not only facts, but also inferences and conclusions drawn from facts [11]. There are different ethical and legal aspects between opponents and proponents from the DNR order, this paper will present an argument of how the process of DNR results in an ethical dilemma for the health care team. The purpose of this essay is to discuss the DNR order in medical futility cases and patients refuse treatment focusing on controversial opinions of this debate and to summarize the opponents and proponents opinions from the legal and ethical perspective, followed by a summary and conclusions. The current researcher are with DNR code status.

\section{Case Scenario}

Mr. A. is a 46-year-old man with multiple myeloma began experiencing acute pain in his right lower abdomen. At 2:00o'clock, Mr. A's wife took him to the emergency department for diagnosis and treatment. Examination revealed lower right abdominal tenderness with rebound pain and lab results confirm high white blood cell count. The physician diagnosed acute appendicitis. When Mr. A's old chart was brought to the emergency department, the physician discovered a DNR order that was placed there during Mr. A's last hospitalization for cancer treatment. The physician approached Mr. A. to discuss this DNR order, particularly its applicability during surgery. Mr. A. insisted that the DNR order must still be followed. The on-call surgical team was preparing for the emergency appendectomy when the physician relayed Mr. A's wishes about the DNR order 
during this surgery. The circulating nurse, whose father also had been diagnosed with multiple myeloma, refused to follow the DNR order. She explained that she had noted from Mr. A's chart that the patient had a wife and 2 small children, and she did not believe that Mr. A. understood how important the remaining time of life would be for him in helping to prepare his family for his impending death.

The author want to address one important question: if Mr. A. stops breathing, or his heart stops beating, should we initiate CPR? In terms of autonomy, beneficial, non mal-efficiency, and all other important ethical principles, which should be always recalled when making our decisions, the issue here is to decide the ethical prospective of his wish not to be resuscitated when his time comes to an end. What about his family? Will they be convinced of his point of view? Will their ethical and moral codes be considering it as ethically acceptable not to resuscitate Mr. A. when he stops breathing or when his heart stops beating?

Within the body of this paper, the authors sincerely will try to persuade you that DNR orders and decisions are ethical rights should be granted to human being uninterrupted by any medical measurements and tries to resuscitate a mortal human being People tend to have an excessively optimistic view of the chances of resuscitation being successful. The principle of autonomy, beneficial, non mal-efficiency, and human dignity should be considered in defending the authors claim of agreeing DNR orders and patients wells.

\section{Background}

It is not appropriate to prolong a person's life at all costs with no regard to its quality or to the potential harms and burdens of treatment [12]. The balancing between risks and benefits of treatment should be applies when decide to use any treatment, including CPR [13]. Elderly with chronic illness have an average survival rate of less than $5 \%$. For those with advanced illness, survival rates are often less than $1 \%$. For example, bedfast patients with metastatic cancer, who are spending $50 \%$ of their time in bed, have a survival rate of $0-3 \%$ [14].

In 1976, the case of Karen Quinlan motivated California to enact the natural death act which was the world's first law allowing withdrawal of life-sustaining support. Since that time, this concept still develops a lot of confusion [15].

In the 1980s, the physician had been placing red colored stickers on the patient charts whose they did not want to resuscitate, then after death, they remove the stickers, so that there was no evidence in the file of any DNR instruction. These unethical practices violated professional obligations to patients and their families [1].

Between 1992 and 2005, there was no improvement in survival among hospitalized elders (65 years old or over) on whom the CPR conducting [14]. In this same study, death proceeded by CPR in the hospital and increased the proportion of survivors discharged home after undergoing CPR decreased.

Despite advances in medical technology and treatment which have allowed health care providers to be able to artificially prolong and preserve life, but patients may put them at risk of ethical dilemma by refusing treatment from the right to die. So, a popular legal issue that places healthcare providers at risk of ethical dilemma is the process of DNR.

The purpose of this literature review was to discuss the legal and ethical debates concerning the DNR order in cases of medical futility and refuse treatment patients.

\section{The Perspectives of those who Oppose DNR}

Legal aspects: The legal implications include falsification rules that prescribe and control social conduct in a formal and legally binding manner [16]. In China or South Korea there is no legislation to date, granting legal approval to withhold CPR support because the notion those patients in similar positions should be treated in a similar manner those come from justice distributive [15].

British Medical Association [17] considered that people who labeled as DNR might be neglected and not be getting the benefits of being treated fairly in response to no CPR, although when a competent young person refusing the CPR illogically; the physicians should explore concerns about euthanasia.

Field, et al. [12] believed that not informing patients of DNR status is illegally, although the physicians should sign the DNR consent.

In Japan, not resuscitate arrested patients for DNR order is legally not accepted and might lead to criminal prosecution for that acceptance of palliative care at the end of life has advanced greatly during the last years to move from that dilemma [15].

Ethical aspects: Ethics is the part of philosophy that deals with the rightness or wrongness of human behavior and concerned with the motivation behind that behaviors [16]. Religion is one of the most sources of moral and ethical codes [18]. According to Islamic instructions taken from the Quran and Sunni, it is deeply believed that the human soul is respected, and to destruct Ka'aba is easier than ending human life. For that, people who disagree with DNR decisions, relying on religion as the main source for their moral and ethical codes.

Schlairet and Cohen [9] against the DNR order and accepted allow natural death concept that guided by the patient's care needs and less on the use of procedural or clinical interventions. They believed that allow natural death order is a positive expression, more acceptable to patients and their families, and the focus is on comfort measurements.

Eiott and Olver [19] believed that decision about DNR is equivalent to a choice between life and death. For that, according to the patient's family, choosing DNR was construed as either the patient was not worth to saving his/ her life or the family did not care enough to save the patient's life.

When a patient's heart seems to be nearing stop, it is generally felt that the morally best approach is to try a new intervention. In contrast to this common practice, Welie and Have [20] argued 
that in most instances, the morally safer route is the DNR. Such intervention is ethically justified only if both of the following necessary conditions have been met: the treatment must be medically futile and there must be consent to the DNR.

\section{The Perspectives of those who Support DNR}

Legal aspects: The American Heart Association announced that CPR was not indicated for all patients. An individual with a terminal, irreversible illness, where death is the expected outcome does not necessarily deserve CPR. Originally, it was referred to the medical system [21].

The American Nurse Association (2012), and American Society of Anesthesiologists (2014) had a consensus about support the patients' rights to self-determination. This right includes that by law the competent patients can refuse life-saving procedures as long as they fully understand the implications of their decision and allow natural death without CPR efforts. Finally, they conclude that the health care providers who attempt to resuscitate patients against their wishes they violate the patients legal right to self-determination. The DNR order is the legal and medical document that reflects the patient's decision and desire to avoid life-sustaining interventions.

Downar [3] illustrated that DNR orders are legally acceptable, and should not be confused with euthanasia or assisted suicide. Welie and Have [20] stated that providing a treatment that is likely to be futile violates the bioethical principle of non malefficiency and may legally constitute battery if the foreseen harm actually occurs.

Ethical aspects: Aacharya [22] believed that end of life decisions by DNR are difficult emergency decisions, but ethical approach simplifies the complexities and facilitates shared decision making process. The CPR guidelines should not just be based on technical and legal issues but also need to encompass the ethical principles. So that, due considerations are incorporated to respect the patients autonomy, without harm and additional sufferings and justifiable equal opportunities in a given context of the society.

Kasule [23] wrote that DNR order is permissible in Islam in cases of a high degree of certainty that resuscitation is futile and will not result in net and lasting benefit to the patient.

In some cases, the decision not to attempt CPR is a clear clinical medical decision. If the medical team believes that CPR will be failed, it should not be started. Decisional authority to use or withhold CPR must reside in providers who can use their training, skills and knowledge to provide the best available care [17].

Irrespective of international variation in decision-making, the DNR decisions form part of an essential framework to uninterrupted the dignified death by a futile resuscitation attempt [12].

In Judaism patients who are terminally ill may be withhold or refused the CPR. Because it may prolonging the dying process and may increase suffering and pain for Jewish patients. Halachic authorities recommend a family to consult with their rabbi in situations involving the consideration of a DNR order [24].

In Catholic patients who are terminally ill permitted to withhold or refuse life-sustaining treatment like CPR if its judged to be extraordinary by the patient and family, and should always be respected and complied with that decision, unless it is contrary to Catholic moral teaching [25].

Finally, the DNR decision is a sophisticated bioethical discussion, although, the DNR orders have a wide cultural differences in their implementation.

\section{The Legal Aspect of DNR in Jordan}

In Jordan there is no legal aspect in Jordanian constitution deals with DNR, but it is considered under article number 3 of medical Jordanian constitution (1985), they indicated that physicians can't end the life of patients, and unable to help in bring death except brain death, the physician can deal with this situation according to international standards,

Although the Jordanian constitution didn't deal with DNR, but if there is evidence that DNR was applied it will be treated as civil and will be punished by prison from 6 months to 3 years.

Taking in consideration according to King Hussein Cancer Center statistic (2012) that caring cancer patients on mechanical ventilator whose medically futile cost the center about 1200 1300 JD daily, so many organization start to talk about DNR and introduce it to community to be familiar with this term and to differentiate between DNR and assist suicide.

Recently in 2011 King Hussein Cancer Center asked (Dar Elefta'a) to has (Fatwa) based on Islam they send to them a conclusion of apply DNR in case of terminally ill patients when they reach the level of nothing to do, and this is will decided by three concerned well trusted, known physicians. Accordingly, the DNR policy was developed in King Hussein Cancer Center to deal and regulate those situations.

The purpose of this literature review was to summarize the different ethical and legal aspects regarding the DNR code status which developed along the time according to different cultures including values, beliefs, and religious background. In this paper the researchers illustrated his agreement position from the DNR order supported by ethical and legal aspects.

\section{Argumentative Essay}

The current researchers are with DNR code status because some people at the end of life continuing of suffer may appear worse than death. Watchinga dying patient suffers can be nearly untolerable for loved ones. The DNR order does not mean patient will die alone and uncared, it means patient will be placed under hospice care when the end is near, and will not die with a tube in any site of body. The CPR might also seem to lack benefit when the patient's quality of life is so poor that no meaningful survival is expected even if CPR were successful at restoring circulatory stability. To that end, the current researchers strives to assist the individual in taking decision in terminally ill and hopeless cases to use the DNR order. 
The DNR still consider a difficult and extraneous concept, in spite of health care providers' efforts to help patients and families to make informed choices. As a Muslim our believe that death as depicted in the holy Qur'an: "Every soul shall have a taste of death" (Holly Quran) and there is another believe every Muslim submits to: "No soul dies except by Allah permission" (Holly Quran). The life of human being in Islam is sacred and wealthy and nobody on earth can end it, so; there is a value and great respect to human life and the exciting civil forbids euthanasia or assisted suicide, in regards to other issues like brain death and DNR, the verdicts of the Islamic been facilitating easy courses medical futility prescribed by specialist doctors. So, the DNR order is permissible in cases of a high degree of certainty that resuscitation is not feasible and will not lead to a net and lasting benefit to the patients permanently.

Focusing on survival after CPR among patients with cancer according to Ehlenbach et al. [14] the survival rate of CPR on television is $66 \%$, but in real the percentage for patients who attempted CPR for cardiac arrest to leave the hospital alive is 20\%, while for older person that has troubles performing activities of daily living because of weakness is $5 \%$, although the survival rate after CPR on individuals with advanced chronic disease is $1 \%$.

Accordingly, the researchers with DNR order because the patients' chances of surviving until discharge could not be improved by CPR. Although, there are many risks involved in performing CPR, including the decrease level of consciousness and chronic coma which sometimes is worse than death, or survival after CPR then death occurring after a long time stay in the intensive care unit.

For that choice is clear between deaths on the oncology ward, surrounded by loved family members, nurses and doctors who knew the patient or death in the intensive care unit after multiple attempt of invasive, painful, and dehumanizing procedures but if the patient's heart stopped to work, the family heart will stop at the same.

\section{Recommendations}

In order to protect the autonomy right of the patient to make health care decisions, certain measures need to be taken to ensure that the potential harm to patients is minimized, in addition legislate law to protect DNR policy and procedure is essential, also, the ethics committee needs to be involved more in such situations.

The current researcher articulate the following fundamental principles to guide action on the DNR issue:

i. Discussion DNR with patients and family might be taken in consider for the following patients: whom CPR may not provide benefits to enhance quality of life and terminal, irreversible illness where death is expected.

ii. Discussion of DNR with patients and family should be included all treatment modalities and balancing between risks and benefits of each treatment.

iii. Alternatives ways of discussing DNR using proper language may be helpful and prevent misunderstanding like DNR orders as giving permission to terminate an individual's life. Although, changing the word from DNR to allow natural death, this concept is more descriptive, have more acceptance and sometimes less threatening.

iv. In health care organizations, the current researchers advocate to have clear DNR policies in place and communicate it to nurses enable them to effectively participate in this crucial aspect of patient care and to be aware and have an active role in developing this policy.

v. The appropriate use of DNR orders, with adequate palliative and end of life care, can minimize the suffering for many dying patients who developed cardiac arrest.

\section{Summary and Conclusions}

There is a different ethical and legal aspect between opponents and proponents from the DNR order. The purpose of this paper was to discuss the DNR order among different cultures in cases of medical futile and patients refuse treatment to summarize the different opinions from the legal and ethical perspective. And current researchers is with applying DNR.

The Islamic religion's views concerning about the DNR decision and have been clarified in a Fatwa from the Presidency of the Administration of Islamic Research and Ifta in Saudi Arabia. The Fatwa states that If three knowledgeable and trustworthy physicians agree that the patient condition is hopeless; the lifesupporting machines can be withdrawn or withheld. The family members' opinion is not included in decision-making as they are unqualified to make such decision.

One reason to choose DNR status that because the patient is suffering and it is better because they have less sufferance. Unfortunately when the loved patients have the opportunity to decide if they want DNR, the family should respect their decision. If they are choosing DNR is because they are suffering a lot illnesses like cancer, which is very painful and traumatic, and when there is no cure for them it is better to practice not to extend their suffering. DNR is the way in which patient and family could reduce the long and painful time before he/she dies.

The author think DNR is the patient's choice and relatives should respect this decision. If I was sick and without a chance of life, I would choose DNR, I think it could be better for me and my family.

\section{References}

1. Tierney E and Kauts V. Do not resuscitate policies in the intensive care unit - the time has come for openness and change. Bahrain Medical Bulletin.2014;36(2):p65

2. British Medical Association. Decisions relating to cardiopulmonary resuscitation: guidance from the British Medical Association, the Resuscitation Council (United Kingdom) and the Royal College of Nursing. British Medical Association House. 2014

3. Downar J, Luk T, Sibbald R W, Santini T, Mikhael J, Berman H, et al. (2011). Why do patients agree to a do not resuscitate or full code order? Perspectives of medical inpatients. Journal of general internal 
medicine. 2011;26(6):582-587. doi: 10.1007/s11606-010-1616-2.

4. Taylor R M, Gustin J L and Wells-DiGregorio S M. Improving do not resuscitate discussions: A framework for physicians. The Journal of Supportive Oncology. 2010;8(1):42-44.

5. American Nurses Association. Registered nurses roles and responsibilities in providing expert care and counseling at the end of life. Silver Spring. 2010; Available from http://nursingworld.org/ dnrposition

6. Garner B A and Black H C. Black's law dictionary. Thomson/West. 2009

7. Taylor R M, Gustin J L and Wells-DiGregorio S M. Improving do not resuscitate discussions: A framework for physicians. The Journal of Supportive Oncology. 2010;8(1):42-44.

8. Yang G M, Kwee A K, \& Krishna L. Should patients and family be involved in do not resuscitate decisions? Views of oncology and palliative care doctors and nurses. Indian Journal Palliative Care. 2012;18(1):52-58. DOI: 10.4103/0973-1075.97474

9. Schlairet M C and Cohen R W. Allow natural death orders: legal, ethical and practical considerations. Hospital Ethics Committee Forum. 2013 25(2):161-171. doi: 10.1007/s10730-012-9181-1.

10. Taylor R M, Gustin J L and Wells-DiGregorio S M. Improving do not resuscitate discussions: A framework for physicians. The Journal of Supportive Oncology. 2010;8(1):42-44.

11. Garner B A and Black H C. Black's law dictionary. Thomson/West. 2009

12. Field R A, Fritz Z, Baker A, Grove A and Perkins G D. Systematic review of interventions to improve appropriate use and outcomes associated with do-not-attempt-cardiopulmonary-resuscitation decisions. Resuscitation. 2014;85(11):1418-1431. doi: 10.1016/j resuscitation.2014.08.024

13. British Medical Association. Decisions relating to cardiopulmonary resuscitation: guidance from the British Medical Association, the Resuscitation Council (United Kingdom) and the Royal College of Nursing. British Medical Association House. 2014

14. Ehlenbach W, Barnato E, Curtis J, Kreuter W, Koepsell T, Devo R et al. Epidemiologic study of in-hospital cardiopulmonary resuscitation in the elderly. New England Journal of Medicine. 2009;361(1): 22-31. doi: 10.1056/NEJMoa0810245.

15. Makino J, Fujitani S, Twohig B, Krasnica S and Oropello J. End-oflife considerations in the intensive care unit in Japan: ethical and legal perspectives. Journal of Intensive Care. 2014;2(1): 9. doi: 10.1186/2052-0492-2-9.

16. Weiss S A and Tappen R M. Essentials of nursing leadership and management. $6^{\text {th }}$ ed. USA: Frank Allston Davis; 2014

17. British Medical Association. Decisions relating to cardiopulmonary resuscitation: guidance from the British Medical Association, the Resuscitation Council (United Kingdom) and the Royal College of Nursing. British Medical Association House. 2014

18. Ellis J and Hartley C. Nursing in today's world: trends, issues and management. Lippincott \& Wilkins. $10^{\text {th }}$ editions. 2012

19. Eliott J and Olver I. Choosing between life and death: patient and family perceptions of the decision not to resuscitate the terminally ill cancer patient. Bioethics. 2008;22(3):179-189.] doi: 10.1111/j.14678519.2007.00620.x

20.Welie J V \& Ten Have H A. The ethics of forgoing life-sustaining treatment: theoretical considerations and clinical decision making. Multidisciplinary Respiratory medicine. 2014;9(1):14. doi: 10.1186/2049-6958-9-14.

21. Selekman J, Bochenek J, Lukens M. Children with chronic conditions. 2013;700-783.

22. Aacharya R P and Maharjan R K. Ethical analysis of medical futility in cardiopulmonary resuscitation. Journal of Clinical Research \& Bioethics. 2014;5(3):1-4. doi:10.4172/2155-9627.1000182.

23. Kasule $0 \mathrm{H}$. Biomedical ethics: an Islamic formulation. Journal of the Islamic Medical Association of North America. 2010;42(1):38-40.

24. American Society of Anesthesiologists. Newsletter liability ethics. Anesthesia. 2014; 78(3).

25. Ethical and religious directives for catholic health care services. $5^{\text {th }} \mathrm{ed}$. United States Conference of Catholic Bishops; 2009. 